\title{
The Relationship between Salesperson's Adaptive Selling Behavior, Rapport, Job Satisfaction, and Organizational Commitment in the Distribution Channel
}

\author{
Hae-Soo Pyun* \\ Department of Business Administration, Namseoul University, 91 Daehak-ro Seongwan-eup, Sebuk-gu, \\ Cheonan-si, Chungcheongnam-do, South Korea; phs@nsu.ac.kr
}

\begin{abstract}
Background/Objectives: This study investigates the relationship between the salesperson's adaptive selling behavior, rapport, job satisfaction, and organizational commitment in the distribution channel. Methods/Statistical analysis: The salespeople working at a distributor of a food-related manufacturer were asked to complete a survey questionnaire. The participants were asked to answer the questionnaire from the perspective of a salesperson. The reliability and the validity were tested. This study tested the hypotheses through Structural Equation Modeling analysis. Findings: This study attempted to examine the relationship between salespersons' adaptive selling behavior, rapport, job satisfaction, and organizational commitment in the distribution channel. The results of hypotheses testing indicated that hypothesis 1 , which stated that adaptive selling behavior of salespeople has positive effects on rapport, was supported. In addition, hypotheses 2 and 3, which stated that rapport has positive influence on job satisfaction and organizational commitment, were supported. Finally, hypothesis 4, which stated that job satisfaction of salesperson has a positive influence on organizational commitment, was also supported. Improvements/Applications: By substantiating the relationship between adaptive selling behavior, rapport, job satisfaction, and organizational commitment, the process of adaptive selling behavior influencing job satisfaction and organizational commitment was identified.
\end{abstract}

Keywords: Adaptive Selling Behavior, Distribution Channel, Job Satisfaction, Organizational Commitment, Rapport

\section{Introduction}

The recent changes in the corporate environment as well as research in related fields indicate the growing trend of long-term business relationships over intermittent ones. In addition, among the various factors that determine corporate performance, service encounter management, which is marked by frequent customer interactions, plays an important role. In particular, in the distribution channel, a relationship-oriented mindset between the corporate and its customers is preferred to a productoriented mindset.

As such, with the increasing influence of the salesperson's attitude and behavior on the success of a corporate, the importance of his/her adaptive selling behavior is gradually growing . Such behavior allows the formation of long-term customer relationships by changing a sales strategy for individual customer's through the collection and utilization of customer information. Furthermore, it positively influences organizational performance. In addition, adaptive selling behavior not only helps form a relationship with customers, but also positively influences job satisfaction of salespeople as well as their commitment to the organization.

However, research on the process by which adaptive selling behavior influences job satisfaction and organizational commitment is relatively insufficient. Thus, the concept of rapport has become increasingly important?

Accordingly, the purpose of the current study is

*Author for correspondence 
as follows. It investigates the relationship between the salesperson's adaptive selling behavior, rapport, job satisfaction, and organizational commitment in the distribution channel. It provides theoretical implications by explaining the role of rapport in adaptive selling behavior and its influence on job satisfaction and organizational commitment. In addition, practical suggestions are presented on specific methods for salespeople to increase their job satisfaction and commitment to the organizations they work for in the distribution channel.

\subsection{Rapport}

Given the significance of rapport in the business world, research in this field is relatively insufficient. Based on existing literature, the definition of rapport can be classified according to its usage in different fields as follows?

In education, rapport is defined as a harmonious relationship based on a shared point of view, expression of personal interest, opinions and emotions, and mutual understanding and satisfaction. In psychology, it is defined as a warm relationship based on understanding, attention, and positive interactions and is used as a means for effective communication in counseling, relationship building, and improving the quality of relationships. In the service and distribution field, it is defined as a close and harmonious relationship or a sense of fellowship based on mutual trust, immediate response to customers' needs, and a capability to build solidarity by understanding customers. Even though rapport is defined differently in different fields, it is basically a supportive and compassionate relationship based on individual perception and mutual understanding.

Initial research on rapport began in the field of psychotherapy. The role of rapport was investigated with focus on the interaction between the therapist and the patient. Mentioned the importance of rapport in the interactions between doctors and patients, and defined rapport as openness, attention, and a warm relationship. 月Discovered that sympathy, warmth, and trust are related to rapport. In addition, analyzed the importance of establishing rapport in diagnosis and creation of treatment plans; while ffound that ensuring good treatment to patients promotes rapport.

Besides psychotherapy, rapport has been frequently researched in various other fields related to education. In Stated that rapport is a harmonious and smooth relationship between teacher and students. Additionally, he defined rapport as a pleasant relationship created by contact between service provider's and customers. Furthermore, research has been conducted on rapport in general interactions. In defined rapport as overall good interactions occurring between individuals 10 , in his research on the formation of rapport based on the position of the target, found that judging individuals felt a better rapport when the target was on their left side.

Research on rapport has been gradually expanded to commercial relationships in the fields of psychotherapy, education and associated areas, service and sales, and general interactions. Specifically, research has been mainly conducted in the fields with frequent interactions with customers such as in services and sales. In Mexpressed rapport as customers' overall good emotion felt in the interactions with salespeople, which included get-alongwell and comfortable relationships. In addition, 12 proved that rapport is formed through smile, eye contacts, friendly greetings, sociability, and listening attentively to the service provider.

Furthermore, looked at rapport from the perspective of the interaction between the service provider and the customer and concluded that rapport is composed of sub-dimensions of special behaviors, formation of commonality, courteous behaviors, touching behaviors, provision of information, a pleasant relationship, and a personal fellowship. In addition ${ }^{13}$ found that an appropriate and dynamic online guide causes a feeling of rapport with the virtual online guide.

The research on rapport is gradually moving from non-commercial interactions to commercial interactions and expanding from an individual dimension to business relationships between corporates. The role and importance of rapport is expected to grow as competition becomes fierce and the quality of business relationships between individuals or corporates becomes more important in the future.

\subsection{Research Hypotheses}

According to adaptive selling refers to the change in behavior of the salesperson based on the information perceived from the nature of the customer and the sales situation during the interaction. Therefore, the level of adaptive selling increases when the selling behavior varies according to selling situations; whereas, it decreases when the selling behavior does not vary across different selling situations. 
Adaptive selling is not always performed in an effective way. When the revenue generated from sales exceeds the cost of recruiting and training salespeople to effectively collect and use information leads to long-term effect of adaptive selling behavior. The four situations when the benefits exceed the costs are as follows:(1) When the salesperson is dealing with various customers with different needs. (2)When large-scale orders are received. (3)When the corporate provides each salesperson with the resources needed to alter the sales strategy. (4)When the salesperson has the capacity to effectively alter the sales ${ }^{14,1}$.

The salesperson will customize the content and style of the sales message based on the characteristics of the individual customer for an effective communication. In conducted a meta-analysis on adaptive selling behavior and customer orientation of salespeople based on the study by ${ }^{14,1}$. In their research, they have corroborated the competition model on antecedents and consequences of adaptive selling behavior and customer orientation.

As adaptive selling behavior uses appropriate sales strategies to incorporate the individual customer's need, the relationship between the seller and the buyer is strengthened; thereby, improving sales performance ${ }^{\text {10 }}$. Some studies on adapting selling behavior have demonstrated its influence on various achievements ${ }^{17-19}$.

In demonstrated that adapting a selling behavior that is appropriate for the individual customer's characteristics and responding to each question in the sales situation increases rapport and reduces the customer's purchase rejection intention. As rapport is defined as pleasant interactions through a personal relationship, such behavior helps form a personal relationship between the salesperson and the buyer, thus inducing positive and continuous interactions.

In 1 also contended that adaptive selling behavior lead to long-term relationships with customers and make effective sales possible. Thus, adaptive selling behavior forms rapport by finding the needs of each individual customer and having a command of sales strategies. Based on the above mentioned rationale, Hypothesis 1 was theorized as follows.

\subsubsection{H1: Adaptive Selling Behavior of Salespeople has Positive Effects on Rapport}

Many researchers are contending about the influences of rapport on performance. They proved that a good relationship between the service provider and the customer yields various outcomes such as higher satisfaction, bonding, trust, purchase and repurchase intention, sales, profits, and order quantity,

In ${ }^{20}$ found that once rapport is formed in the form of harmonious empathy between the salesperson and the customer, a sympathetic relationship, or fellowship, the likelihood of purchasing a service or product increases. In mentioned that rapport is the highest level of interactions the seller and customer can achieve and it has a significant influence on the buying decision process.

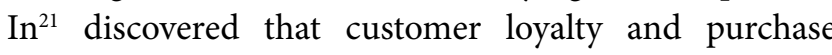
intention can be increased by forming a rapport with the customer because rapport increases the level of customer satisfaction recovery after a service failure. Moreover, it increases the customers' revisit intention and reduces the customer's complaint intention and the effect of negative word-of-mouth.

In proved the relationship between rapport and customers' repurchase intention. In analyzed the influence of rapport on trust and satisfaction in the service industry and found that rapport provides customers with psychological comfort and satisfaction. Moreover, while a rapport is being built, the need for knowledge about the customers' need increases.

Many studies have demonstrated that rapport influences economic and relational performance. That is, studies found out that rapport has a positive influence on relational performance such as trust, bonding, and satisfaction, and economic performance such as increases in sales, profits, and order quantity. Furthermore, the rapport built by forming positive relationships with customers increases the job satisfaction of the salespeople and their commitment to the organizations they work for. Moreover, job satisfaction increases the commitment of salespeople to the organizations they work for. Based on the rationale above, hypotheses 2,3 , and 4 were theorized as follows.

\subsubsection{H2: Rapport has a Positive Influence on Job Satisfaction}

\subsubsection{H3: Rapport has a positive influence on organizational commitment.}

\subsubsection{H4: Job satisfaction has a positive influence on organizational commitment.}




\section{Methods and Results}

\subsection{Methods}

\subsubsection{Measurements}

This study attempted to examine the relationship between salesperson's adaptive selling behavior, rapport, job satisfaction, and organizational commitment in the distribution channel. For this purpose, each variable was measured based on previous studies. All items were measured on a on a five point Likert scale that ranges from (1), which implies strongly disagree, to (5), which implies strongly agree.

\subsubsection{Samples}

This study deals with the relationship between corporates and their customers. Accordingly, salespeople at a manufacturing company were requested to respond to questions about their adaptive selling behavior, rapport with major business partners, job satisfaction, and organizational commitment. The salespeople working at a distributor of a food-related were asked to complete a survey questionnaire. The participants were asked to answer the questionnaire from the perspective of a sales person that represents the organization and not from the perspective of the customers, who are the main business partners. Data were collected from 248 salespeople and the final analysis was conducted on a total of 234 responses.

The characteristics of the participants were as follows. More than $80 \%$ of the participants were 40 years or older with 33.3\%above 50 years, $50.9 \%$ between 40 and 49 years, and $13.7 \%$ between 20 and 30 years. In terms of the length of employment, almost $80 \%$ of the entire participants have been employed for three years or longer with $63.2 \%$ for five years or longer, $14.1 \%$ between three to five years, $15,4 \%$ between one to two years $15.4 \%$, and $5.1 \%$ under one year. As the participants were found to have sufficient knowledge and experience about their job and the organization they worked for, they were deemed to be appropriate subjects for this study.

\subsection{Results}

\subsubsection{Reliability and Validity}

The reliability of the measurement instrument and the validity of the measurement model were tested through confirmatory factor analysis.

Cronbach's a coefficient was used to test the reliability of the theoretical variables measured with multiple items. In 2 suggested that a Cronbach's a coefficient equal to or greater than 0.7 is indicates the reliability of a model for preliminary research, 0.8 or greater for basic research, and 0.9 or greater for applied research. However, a value of 0.6 or greater is also acceptable in the initial stages of research. The result of the reliability test of each variable is depicted in Table 1. The results of the analysis of each item, excluding those that lower the goodness-of-fit of the model, produced Cronbach's a coefficient values equal to or greater than 0.8 ; hence, the measurements were considered to be carried out at a reliable level.

Table 1. Reliability and validity analysis results

\begin{tabular}{|l|c|c|c|c|c|c|c|c|}
\hline Construct & Item & $\begin{array}{c}\text { Standardized } \\
\text { factor loadings }\end{array}$ & S. E & C. R & P & AVE & $\begin{array}{c}\text { Construct } \\
\text { Reliability }\end{array}$ & Cronbach'a \\
\hline Adaptive Selling & A1 & .645 & & & & .767 & .867 & .647 \\
Behavior & A2 & .783 & .232 & 5.725 & .000 & & & \\
\hline Rapport & R1 & .770 & & & & .755 & .902 & .756 \\
& R2 & .739 & .107 & 9.128 & .000 & & & \\
& R3 & .704 & .100 & 8.859 & .000 & & & \\
\hline Job Satisfaction & J1 & .799 & & & & .829 & .951 & .916 \\
& J2 & .852 & .073 & 13.388 & .000 & & & \\
& J3 & .864 & .071 & 13.433 & .000 & & & \\
& J4 & .838 & .076 & 12.878 & .000 & & & \\
\hline Organizational & O1 & .737 & & & & .821 & .932 & .870 \\
Commitment & O2 & .871 & .092 & 12.421 & .000 & & & \\
& O3 & .900 & .093 & 12.759 & .000 & & & \\
\hline
\end{tabular}


Validity indicates the accuracy in measuring a concept or an attribute. This study measures contents validity, convergent validity, and discriminant validity. The content validity is the extent to which the measurement instrument is actually measuring the characteristics of the concept to be measured and it is evaluated by the subjective judgment of the expert. For this study, a questionnaire was created based on previous studies and an in-depth interview with an expert. In addition, interviews with hands-on workers were conducted and the content validity of the questionnaire was ensured with help from a current professor of marketing and some doctoral students.

The convergent validity is the degree of correlation between two or more measurement instruments on one concept and it is evaluated by the magnitude of standardized loading factor, Average Variance Extracted (AVE), and the Construct Reliability (CR). A standardized loading factor greater than 0.7, AVE greater than 0.5 , and CR greater than 0.7 , then indicates convergent validity. In this study, most measurement models indicated convergent validity as depicted in Table 1 .

The discriminant validity is related to the degree of difference between two concepts. An AVE value of a concept that is greater than the value of R-squared between two concepts indicates the discriminant validity of the concept. The results of the discriminant validity test on each concept are depicted in Table 2. In this study, the comparison between the AVE of each concept and the R-squared between concepts indicated that the discriminant validity was ensured for all measurement concepts.

Table 2. Discriminant validity results

\begin{tabular}{|c|c|c|c|c|}
\hline Construct & AVE & $\mathbf{r}$ & $\mathbf{r}^{2}$ & $\begin{array}{c}\text { Discriminant } \\
\text { Validity }\end{array}$ \\
\hline $\begin{array}{c}\text { Adaptive } \\
\text { Selling Behavior } \\
\leftrightarrow \\
\text { Rapport }\end{array}$ & $\begin{array}{c}\text { Adaptive } \\
\text { Selling Behavior } \\
(.767), \\
\text { Rapport } \\
(.755)\end{array}$ & .414 & .171 & $\mathrm{O}$ \\
\hline $\begin{array}{c}\text { Adaptive } \\
\text { Selling Behavior } \\
\leftrightarrow \\
\text { Job } \\
\text { Satisfaction }\end{array}$ & $\begin{array}{c}\text { Adaptive } \\
\text { Selling Behavior } \\
(.767), \\
\text { Job } \\
\text { Satisfaction } \\
(.829)\end{array}$ & .202 & .040 & $\mathrm{O}$ \\
\hline $\begin{array}{c}\text { Adaptive } \\
\text { Selling Behavior } \\
\leftrightarrow \\
\text { Organizational } \\
\text { Commitment }\end{array}$ & $\begin{array}{c}\text { Adaptive } \\
\text { Selling Behavior } \\
(.767), \\
\text { Organizational } \\
\text { Commitment } \\
(.821)\end{array}$ & .217 & .046 & $\mathrm{O}$ \\
\hline $\begin{array}{c}\text { Rapport } \\
\leftrightarrow \\
\text { Job } \\
\text { Satisfaction }\end{array}$ & $\begin{array}{c}\text { Rapport } \\
(.755), \\
\text { Job } \\
\text { Satisfaction } \\
(.829) \\
\end{array}$ & .296 & .088 & $\mathrm{O}$ \\
\hline $\begin{array}{c}\text { Rapport } \\
\leftrightarrow \\
\text { Organizational } \\
\text { Commitment }\end{array}$ & $\begin{array}{c}\text { Rapport } \\
(.755), \\
\text { Organizational } \\
\text { Commitment } \\
(.821)\end{array}$ & .326 & .106 & $\mathrm{O}$ \\
\hline $\begin{array}{c}\text { Job } \\
\text { Satisfaction } \\
\leftrightarrow \\
\text { Organizational } \\
\text { Commitment }\end{array}$ & $\begin{array}{c}\text { Job } \\
\text { Satisfaction } \\
(.929), \\
\text { Organizational } \\
\text { Commitment } \\
(.821)\end{array}$ & .741 & .549 & $\mathrm{O}$ \\
\hline
\end{tabular}




\subsubsection{Hypotheses Testing}

This study tested the hypotheses through Structural Equation Modeling analysis. The results of the test are presented in Table 3. The goodness-of-fit index of model was at the acceptable level $\left(\mathrm{x}^{2}=49.043, \mathrm{df}=45, \mathrm{p}=.315, \mathrm{x}^{2} /\right.$ $\mathrm{df}=1.090, \mathrm{RMR}=.015, \mathrm{GFI}=.962, \mathrm{AGFI}=.935, \mathrm{IFI}=.997$, TLI=.996, CFI=.997.). Therefore, it was determined as appropriate for the hypotheses testing.

The results of hypotheses testing indicated that hypothesis 1 , which stated that adaptive selling behavior of salespeople has positive effects on rapport, was supported. In addition, hypotheses 2 and 3, which stated that rapport has positive influence on job satisfaction and organizational commitment, were supported. Finally, hypothesis 4, which stated that job satisfaction of salesperson has a positive influence on organizational commitment, was also supported.

\section{Conclusion}

This study attempted to examine the relationship between salespersons' adaptive selling behavior, rapport, job satisfaction, and organizational commitment in the distribution channel. To this end, the salespeople working at a distributor of a food-related manufacturer were asked to select their main business partners and respond to a survey questionnaire from their perspective. Data were collected from 248 salespeople, and the final analysis was conducted on a total of 234 responses. Reliability and validity tests were conducted through the collected data, and Structural Equation Modeling was utilized for testing the hypotheses. The results supported all four hypotheses.

The present study is significant for the following reasons. First, by substantiating the relationship between adaptive selling behavior, rapport, job satisfaction, and organizational commitment, the process of adaptive selling behavior influencing job satisfaction and organizational commitment was identified. Theoretical implications, which contribute to the existing literature on rapport, are presented. Second, practical implications for corporate sales managers were provided by determining the factors that are important for job satisfaction and organizational commitment of salespeople.

The limitations of this study and the prospects of future research in this field are as follows: First, other factors need to be considered to better understand the process by which adaptive selling behavior influence job satisfaction and organizational commitment. In future studies, the mediating role needs to be identified by comprehensively considering other factors. Second, this study is limited to salespeople in the food industry. It is necessary to expand this research to various industries. Third, rapport can be further developed as time passes. It is necessary to conduct an inter-temporal comparative analysis in its research.

Table 3. Hypotheses testing results

\begin{tabular}{|l|l|c|c|c|c|l|}
\hline Hypotheses & Paths & Estimates & S. E & C. R & P & Results \\
\hline H1 & $\begin{array}{l}\text { Adaptive } \\
\text { Selling Behavior } \\
\rightarrow \\
\text { Rapport }\end{array}$ & .641 & .154 & 5.685 & .000 & Supported \\
\hline H2 & $\begin{array}{l}\text { Rapport } \\
\text { Job } \\
\text { Job } \\
\text { Satisfaction }\end{array}$ & .375 & .104 & 4.448 & .000 & Supported \\
\hline Happort \\
$\begin{array}{l}\text { Ra } \\
\text { Organizational } \\
\text { Commitment }\end{array}$ & .148 & .069 & 2.392 & .017 & Supported \\
\hline H4 & $\begin{array}{l}\text { Job } \\
\text { Satisfaction } \\
\text { Organizational } \\
\text { Commitment }\end{array}$ & .712 & .077 & 8.416 & .000 & Supported \\
\hline
\end{tabular}




\section{Acknowledgment}

Funding for this paper was provided by Namseoul University.

\section{References}

1. Franke GR, Park JE. Salesperson adaptive selling behavior and customer orientation: a meta-analysis. Journal of Marketing Research. 2006 Nov; 43:692-702.

2. Fatima JK, Razzaque MA. Roles of trust on rapport and satisfaction in services. Asia Pacific Journal of Marketing and Logistics. 2014; 26(4):566-78.

3. Gremler DD, Gwinner KP. Customer-employee rapport in services relationships. Journal of Service Research. 2000; 3(1):82-104.

4. Harrigan JA, Rosenthal R. Physicians' head and body positions as determinants of perceived rapport. Journal of Applied Social Psychology. 1983 Nov-Dec; 13:496-509.

5. Kritzer. Rapport in therapist-client interactions: an ecological analysis of the effects of nonverbal sensitivity and interactional synchrony [Doctoral Dissertation]. USA, Hofstra University; 1990.

6. Barnett PB. Rapport and the hospitalist. Disease-a Month. 2002; 48(4):250-9.

7. Allen A, Montgomery M, Tubman J, Frazier L, Escovar L. The effects of assessment feedback on rapport-building and self-enhancement process. Journal of Mental Health Counseling. 2003; 25(3):165-82.

8. Bernieri JSG, Davis JM, Grahe JE. Dyad rapport and the accuracy of its judgment across situations: a lens model analysis. Journal of Personality and Social Psychology. 1996; 71(1):110-29.

9. Tickle-Degnen L, Rosenthal R. Group rapport and nonverbal behaviors, in group processes and intergroup relations, review of personality and social psychology. Hendrick C editor. Newbury Park, CA: Sage. 1987; 9:113-36.

10. Puccinelli NM, Tickle-DegnenL, Rosenthal R. Effect of target position and target task on judge sensitivity to felt rapport. Journal of Nonverbal Behavior. 2004; 28(3):211-9.

11. Dell SA. Relational communication and organizational customer loyalty [Doctoral dissertation]. USA, University of Denver; 1991.

12. Ford WSZ, Etienne CN. Can I help you? A framework for the interdisciplinary research on customer service encounters. Management Communication Quarterly. 1994 May; 7(4):413-41.

13. Al-Natour S, Benbasat I, Cenfetelli RT. Creating rapport and intimate interactions with online virtual advisors. Proceedings of the Sixth Annual Workshop on HCL Research in MIS, Montreal. 2007 Dec; 8:35-40.

14. Weitz BA, Sujan H, Sujan M. Knowledge, motivation, and adaptive behavior: a framework for improving selling effectiveness. Journal of Marketing. 1986; 50(4):174-91.

15. Spiro RL, Weitz BA. Adaptive selling: conceptualization, measurement, and nomological validity. Journal of Marketing Research. 1990 Feb; 27:61-9.

16. Jaramillo F, Locander WB, Spector PE, Harris EG. Getting the job done: the moderation role of initiative on the relationship between intrinsic motivation and adaptive selling. Journal of Personal Selling and Sales Management. 2007; 27(1):59-74.

17. Marshall GW, Goebel DJ, Moncrief WC. Hiring for success at the buyer-seller interface. Journal of Business Research. 2003 Apr; 56:247-55.

18. Park JE, Deitz GD. The effect of working relationship quality on salesperson performance and job satisfaction: adaptive selling behavior in Korean automobile sales representatives. Journal of Business Research. 2006 Feb; 59:204-13.

19. Park JE, Holloway BB. Adaptive selling behavior revisited: an empirical examination of learning orientation, sales performance, and job satisfaction. Journal of Personal Selling and Sales Management. 2002; 23(3):239-51.

20. Brooks M. Instant rapport. Warner Books, New York; 1989.

21. DeWitt TM, Brady K. Rethinking service recovery strategies. Journal of Services Research. 2003; 6:193-207.

22. Nunnally JC. Psychometric theory. Second Edition McGraw Hill Book Company, New York; 1978. 